\section{Research for Optimum Nutrition}

Nutrition science has made great strides in the past, but the opportunities for further progress are limitless. Long-term investments in fundamental research represent an approach historically proved to offer the best returns in the long run. There is a constant exchange, of course, between basic and applied science. Research in nutrition, applied as well as fundamental, will help workers throughout the world in promoting health and long life.

A constructive approach requires that we strive to attain, and to maintain, optimum health while repairing damage. Fortunately, the population as a whole has lost much of its complacency concerning nutrition. Food technology, through food fortification, increased availability and palatability of foods, and other innovations, is a major aspect of the public health approach through which the need for specific nutritional therapy may some day be eliminated. The human body is remarkably adaptable, and inherent abnormalities of digestion and metabolism may lead to compensatory dietary practices. Unfortunately, however, the contrary is frequently the case; selection and consumption of food often obey a misleading appetite, and the result may be damage and disease.

Nutrition science is only beginning its venture into gerontology and the major chronic diseases. Whether substantial contributions are achieved in the near future depends largely on the cooperative efforts of many individuals and groups. No longer is scientific progress by lone investigators the rule, as in the days of Pasteur and Ehrlich. Many disciplines must coordinate their attack. Nutrition research and theory must be converted to food therapy, nutrition knowledge, to public health gains.

\title{
Enrichment . . . . .
}

\section{a Public Health Approach to Better Nutrition}

\author{
By William H. SEBRELL, Jr., M.D.
}

$\mathrm{W}$ $\mathrm{E}$ ARE inclined in these modern times to take our knowledge of nutrition for granted and to underestimate the importance of its application. Consider for a moment the problem of malnutrition in earlier days. Vasco de Gama, in his search for a water route to the East, rounded the Cape of Good Hope and returned with only a third of his crew, the rest having died of scurvy. At one time the channel fleet of the British Navy could not be manned because of the prevalence of scurvy among the crews. In the late 19 th century, 40 percent of the seamen in the Japanese Navy died of beriberi; and in Italy at about the same time, the reported cases of pellagra exceeded 104,000. One by one, these and other serious diseases re- sulting from specific dietary deficiencies have yielded to science.

The progress of nutrition research, however,

Dr. Sebrell presented this paper at Toronto on January 26, 1953, as Canada inaugurated a program of flour and bread enrichment. Speaking before the First Nutrition and Enrichment Conference of the Baking and Milling Industries, he characterized the Canadian enrichment program as "one more forceful blow in the prevention of malnutrition... further indication of the increasing role of enrichment in the health and strength of nations." His discussion, here somewhat condensed, appears in full in The Canadian Hospital for June 1953. 
is only part of the story of effort in the nutrition field. The complete picture includes what might be termed the public health movementthe application of nutrition knowledge through industry, agriculture, education, government, and, of course, the medical profession. In this movement, an important trend in Europe and North America has been a broadening of the attack to extend preventive measures to successively larger groups of people.

\section{Early Applications}

Available knowledge prior to World War I was used mainly for the prevention or alleviation of dietary deficiency diseases in the individual. Citrus fruits and juices were fed to seamen, and later to children, to treat and prevent scurvy; cod liver oil was used in treating rickets; extracts of rice polishing, in beriberi. The next step, an organized public health approach, was the planned distribution of preventive dietary supplements, such as cod liver oil, butter, and iodized salt. Meanwhile, the isolation of vitamins progressed; and just prior to World War II, it became practical to improve staple foods with synthetic nutrients as a means of preventing dietary diseases in large populations.

In the United States, on a growing scale, vitamin $\mathrm{D}$ was added to milk and vitamin $\mathrm{A}$ to margarine. Thus, the principle being used in the control of goiter with iodized salt-the fortification of food-was extended to rickets and vitamin A deficiency. Early in 1941 the same broad approach was applied to the prevention of beriberi, pellagra, ariboflavinosis, and iron-deficiency anemia, when enriched bread and flour were introduced.

Public preference for highly refined foods had left the American diet deficient in many important respects. For example, the patent milling process, by removing most of the germ and bran shorts from flour, reduces the thiamine content about 90 percent and the niacin, riboflavin, and iron 70 to 85 percent. White bread and refined sugar and fats are widely preferred for taste, appearance, and durability. Together they furnish a large proportion of our calories. This resulted in less than satisfactory amounts of essential nutrients per capita and led inevitably to dietary diseases, especially in poorly fed sections of the population.

The enrichment of bread and flour had therefore received the enthusiastic endorsement of the Nation's foremost nutrition scientists, including the American Medical Association's Council on Foods and Nutrition and the $\mathrm{Na}$ tional Research Council's Food and Nutrition Board. With the advice of these groups, the Food and Drug Administration established standards for enriched wheat products, permitting specified amounts of the four nutrients, thiamine, niacin, riboflavin, and iron. Certain other substances, such as calcium, vitamin $\mathrm{D}$, and wheat germ, can also be added, but this has not been done on a wide scale. Calcium and other nutrients are often supplied in bread through use of dry milk solids, a practice that should be extended.

\section{Status at Pearl Harbor}

By the time the country entered World War II, the enrichment of flour and bread had become well established. Within another year about three-quarters of the bakers' white bread and almost all family flour was enriched on a voluntary basis. A further step in the application of nutrition knowledge was now feasiblenationwide control of specific dietary diseases; and a program to that end was soon launched. During periods of war, foods that are costly to produce tend to become scarce, and greater dependence is placed upon cereal products, the least expensive foods in terms of man-hours and acreage. Consequently, it was apparent that cereals as an important part of the national diet must contain essential nutrients.

Serious consideration was given to the possible use of long-extraction flour, which retains some of the vitamins and mineral-rich portions of the wheat. Some reasons against requiring the product, besides the general preference for white flour, were its perishability, its limitations for pastry, and the dependence of the animal food industry upon the residues of patent milling. Moreover, it was believed that the prohibition of white bread and flour would be difficult or impossible to enforce in the United States. There was also the success achieved with voluntary enrichment, as well as the fact 
that enriched products were better supplied with the nutrients in question-an important health consideration.

In January 1943 the Federal Government issued war food order No. 1, requiring the enrichment of all bakers' white bread with thiamine, niacin, riboflavin, and iron. Subsequently, the nationwide nutrition movement brought about improved agricultural practices, better nutrition education, a national school lunch program, and advances in food handling, preservation, and distribution. Since October 1946 when the war food order ceased to be effective, enrichment of bread and flour has not been required by Federal regulation, but more than half the States have passed laws making enrichment mandatory. In the remaining States, voluntary enrichment is being continued extensively, according to recent surveys by the industry.

\section{Assessment After a Decade}

After nationwide practice of more than 10 years, what have been the health gains due to better nutrition, and to what extent are they attributable to the enrichment program? What, if any, have been the harmful effects? What is the future of food enrichment as a means of attacking malnutrition throughout the world?

Unequivocally, we can say that there is no evidence of harm from the program, nor reason to expect it. If the diet contains slightly more than the required amount of a nutrient, the excess is simply excreted. These statements apply also to the products commonly fortified with iodine and vitamins $\mathbf{A}$ and $\mathbf{D}$. There is a wide margin of safety between recommended and harḿful levels.

As to health gains, on the other hand, there is ample evidence of the efficacy of the nutrition program and every reason to ascribe much of the success to bread and flour enrichment. No more dramatic history of health progress could be cited than that of pellagra in the United States. In the 1920's and 1930's, this was our most serious deficiency disease.

\section{Pellagra and Niacin}

Pellagra results from a diet low in two nutrients, either of which will prevent it-the vitamin niacin and the protein component tryptophan. Mild cases are much commoner than extreme cases, and mortality rates reflect only a small proportion of the pellagra problem. In a region of high prevalence, at least 33 cases per death were found in 1917, before control measures were instituted. At one time, an estimated 200,000 were afflicted with pellagra in the United States. In 1928, at the height of reported mortality, there were approximately 7,100 pellagra deaths, or 6 per 100,000 population. Nearly 98 percent of those occurred in southern States where most of the available land was used for nonfood crops, such as cotton and tobacco.

For the past 25 years, the death rate from pellagra has shown a general downward trend. This is attributable not only to the national nutrition program, but also to better medical treatment, shifting of the population, extensive changes in agricultural practices, and gradual economic improvement in the south through the establishment of industry there.

It is interesting to note the pellagra mortality at key points in the nutrition program. By 1937 , the year niacin was isolated, pellagra mortality was about half that of 1928 , or 2.5 per 100,000. Cures with niacin were reported that year by several clinicians, and thereafter the decline was more rapid. In 1943, 2 years after niacin-enriched foods appeared on the market, the rate was 1 ; by 1950 it had dropped to 0.2 , representing an unprecedented low of 260 reported deaths in the entire country.

In North America, mortality data do not reflect the true health importance of the deficiency diseases, since very few affected persons die. It is the number of cases-the people limited in their capacity to work and enjoy life-with whom we are especially concerned. Nearly all of the estimated 200,000 cases of 20 years ago were in the south. In contrast, among 10,000 recent admissions to the Hillman General Hospital in Birmingham, Ala., not a single pellagrin was found-and this, at one of our permanent pellagra research centers in an area where the disease was once rampant.

At the Cincinnati General Hospital, where 34 cases were diagnosed in 1939 , only 1 case was seen from 1946 to 1948 . If enrichment had done 
nothing but help control this one disease, it would have paid for itself many times over in lives saved and people rehabilitated.

Ëven among chronic alcoholics, once commonly afflicted, pellagra has become rare. In 1948 and 1949, the Army Medical Nutrition Laboratory examined approximately 16,000 alcoholic inmates of the Chicago House of Correction and found only 2 with pellagra, 3 with ariboflavinosis, and 1 with possible beriberi. The decline of those diseases among alcoholics clearly dates from the introduction of enrichment.

\section{B-vitamin Deficiencies}

Beriberi is a disease resulting from lack of thiamine, another vitamin of the B group. Like other deficiency diseases, beriberi has no geographic limitations, though more than 90 percent of the cases are reported among riceeating peoples. How serious it can be as a public health problem is shown by the fact that in the Philippines in 1948 beriberi was second only to tuberculosis as a cause of death. Small outbreaks have occurred in such places as Australia, Iceland, and Labrador. In the United States, Great Britain, and other western countries, beriberi has been frequently reported among chronic alcoholics and the inmates of institutions; but it is not an important cause of death among peoples consuming a variety of foods. In its less severe forms, however, there was evidence that thiamine deficiency was sufficiently prevalent in the United States to warrant addition of the vitamin to flour and bread.

Ariboflavinosis-riboflavin deficiency disease-is reported frequently in various parts of the world. It often occurs in conjunction with other B-vitamin deficiencies, especially pellagra. Ariboflavinosis was not recognized as affecting humans until 1939. As a result, the incidence in the United States was not accurately estimated, but there is no doubt of its former prevalence.

Like pellagra, these B-vitamin deficiency diseases-beriberi and ariboflavinosis-have declined in the United States as a result of improved nutrition to which enrichment has demonstrably contributed.

\section{General Effects of Enrichment}

While the demonstrated prevention of specific deficiency diseases is the real test of enrichment, other evidence of its effect on the nutritional status of the population should not be ignored. Over the past 10 or 15 years, there has been a general elevation in the nutritive value of our national diet. This means primarily a higher vitamin, mineral, and protein intake. As shown in studies by the U. S. Department of Agriculture, the most striking increases have been in thiamine, niacin, riboflavin, and iron-with a sharp rise beginning about 1941, when enriched bread and flour were introduced. In 1945 and 1946, the peak years of per capita consumption, these four nutrients exceeded prewar levels by a third to a half.

The average American in 1945, as compared with what he would have received without enrichment, obtained in his food 27 percent more thiamine, 19 percent more niacin, 12 percent more riboflavin, and 17 percent more iron. The benefits were greatest among the lower income group, whose diet is poorest and incidence of deficiency diseases highest.

Thus, we are able to trace various specific health gains due to better nutrition and even to assign a considerable measure of that progress to the enrichment program. Other advances in health are undoubtedly associated with the nutrition movement, but their contribution is harder to prove. Maternal and infant deaths, for example, have declined to unprecedented levels, and nutritional changes have been significant. Similarly, there have been appreciable increases in growth rate and stature. Downward trends in mortality from infections, particularly tuberculosis, have paralleled the elevation of nutritional status. In short, the benefits of improved nutrition have exceeded our most optimistic expectations.

\section{Problems Ahead: Chronic Diseases}

By no means, however, does all this imply that our national diet is now perfect, nor that malnutrition in the United States is a thing of the past. I have discussed only the advances, the favorable trends. Many problems still confront us, some of which mount in significance 
as various factors lengthen the life span and increase the number of older people in the population.

One such problem is our high mortality from chronic diseases frequent among the aged, such as the cardiovascular diseases, cancer, diabetes, and cirrhosis of the liver. Another problem, the extent of which is uncertain, is that of borderline dietary deficiencies-conditions presenting an indefinite clinical picture, but nevertheless one of suboptimal health.

With regard to the problems attacked through enrichment, we know that anemia, by generally accepted standards, is still widespread in the United States, especially among women. This is thought to be largely nutritional in origin. The commonest form of anemia-secondary, or hypochromic-is attributed to iron deficiency; but the incidence has shown little change, despite the increase in the average consumption of iron. Does this mean that the problem is overestimated because of an unrealistic health standard, that iron is poorly utilized, or that iron deficiency is not responsible for the condition? Only further research can provide an answer.

There are many other important research problems in nutrition. Our approach to these must remain broad. The history of science shows conclusively that the long-range point of view - the emphasis upon fundamental investigation, often with little promise of practical reward-is the most productive approach in the long run. Practical applications of basic knowledge will suggest themselves.

For the most part, the remaining nutrition problems require further research and intensive education. Enrichment should certainly be continued and, along some lines, extended. Not only would a relaxation of that effort permit a relapse of nutritional status, with a high probability of increasing deficiency disease, it would also undermine our nutritional foundation, the bulwark of cheap staple foods-bread, flour, milk, salt, margarine, and so forth-upon which the Nation's health would depend in an economic or other calamity. The National Research Council has described enrichment as "low-cost insurance against certain nutritional ills."

Nutritionists and allied workers in the United
States appreciate the importance of developing their programs in full recognition of world nutritional needs. Today, serious world problems critically involve us all-problems that often reflect the ratio of food supply to population. Established techniques intensively applied can often remedy the local shortage of a vitamin-as shown recently in the Philippines, where rice enrichment and other measures reduced beriberi deaths in an experimental zone by 90 percent or more. The successful expansion of this program in the Philippines would be a major public health advance for that country.

\section{Enrichment, Education, Research}

Enrichment is a powerful weapon against malnutrition, but it must not become the sole or final effort. Nutrition research must be intensified ; and sound programs of nutrition education-the essential link between professional knowledge and the improvement of food practices-must be vigorously pursued.

These are aspects of the public health program in nutrition to which industry and government can contribute, as they have done notably in the past. Let me stress the necessity of cooperation between industry and government in this movement. It has been our experience that businessmen are deeply interested in the Nation's health, that they recognize its great importance and that they want to be helpful and to do the right thing. They also have their feet on the ground and properly act only when strongly convinced. Such cooperation is highly productive in the field of education. Here, industry can bring to bear effective techniques and attractive media, which government agencies cannot obtain. Whenever government and industry participate in a sound program of nutrition education, as they have done in the United States, material progress in public health can be expected.

Nutrition education, as its main objective, should seek to establish public demand for an adequate diet, taking into account a wide range of consumer incomes. The physician, health officer, nurse, teacher, and other key persons in the community must be prepared to guide individuals and institutions in selecting the right foods; and for this, they must be skilled in the 
practicalities of feeding-food values relative to cost. In commercial advertising, a greater effort should be made to show the proper relation of the promoted product to good nutrition as a whole. Finally, community leaders, advertisers, nutritionists, and others in the role of educator should focus primarily upon the housewife, who selects and prepares the meals and guides in the formation of food habits.
Sound food habits must always be the major objective. It is unlikely, however, that enrichment will ever be entirely superseded by informed food selection, since food values vary seasonally and geographically, and selection to some extent is economically determined. The modern attack upon malnutrition should bo spearheaded by enrichment, backed by educiation, and controlled by research.

\section{CIRCULARIZATION \\ Of PHR Free Mailing List}

Early in October Public Health Reports will send a mailing list circularization inquiry to all addresses on its official and free mailing lists-not, however, to paid subscribers.

Required by the Joint Congressional Committee on Printing, this circularization necessitates return of a special card confirming correctness of the address and number of copies of Public Health Reports sent each month. Health departments, teaching institutions, libraries, and others will want to devote special attention to the circularization inquiry, as the mailing list is composed for the most part of office and position titles, rather than of individual names.

Watch for the special postal card. Complete it fully and return it promptly. Failure to respond by the date specified on the card sent each addressee will result in removal of the name from the mailing list. 